\title{
Designing for performative tangible interaction
}

\section{Jennifer G. Sheridan*}

BigDog Interactive, InfoLab21, South Road, Lancaster LA1 4WA, UK

E-mail: jennifer@bigdoginteractive.com

*Corresponding author

\section{Nick Bryan-Kinns}

Interaction, Media and Communication Research Group, School of Electronic Engineering and Computer Science, Mile End, London E1 4NS, UK

E-mail: nickbk@dcs.qmul.ac.uk

\begin{abstract}
We propose that designing tangibles for public interaction requires an understanding of both functional and non-functional aspects informed by Live Art theories. In this paper, we outline design requirements for performative tangible interaction, propose a framework for assessing performative interaction and demonstrate its use through four case studies of the iterative redesign of a highly portable, tangible exertion interface. By reflecting on our experience of designing for performative interaction we develop guidelines for developing multi-participant Digital Live Art.
\end{abstract}

Keywords: acceleration; accelerometers; design; Digital Live Art; embedded; evaluation; exertion; guidelines; interfaces; multi-participant; performance; public; tangible; wireless.

Reference to this paper should be made as follows: Sheridan, J.G. and Bryan-Kinns, N. (2008) 'Designing for performative tangible interaction', Int. J. Arts and Technology, Vol. 1, Nos. 3/4, pp.288-308.

Biographical notes: Jennifer Sheridan is Director of BigDog Interactive, a company that employs programmers and artists to create interactive installations and live performance events. Currently, she is the Research Officer on the EPSRC-funded project 'Designing Tangibles for Learning' (EP/F018436) at the London Knowledge Lab. Her research explores how Human-Computer Interaction (HCI) and Live Art measures can be used to understand performative interaction and to mediate 'wittingness'. She recently collaborated to create the world's first live, generated three-dimensional spatialisation together with live composition created by real-time movement for the EPSRC/AHRC Design for the twenty-first century 'Emergent Objects: Designing the Technology Interface through Performance', subproject 'Hoverflies'.

Nick Bryan-Kinns lectures on Graphical User Interface design at Queen Mary, University of London. His EPSRC-funded research focuses on exploring the nature of mutually engaging interaction, in particular, group music collaboration using novel shared musical instrument. He was recently involved in two EPSRC-funded networks focussing on the art-computer cross-over and designing for the twenty-first century, and was co-chair of the BCS-HCI 
conference in 2006. He is currently a co-investigator on the EPSRC-funded Centre For Digital Music Platform Grant at Queen Mary. In 1998, he was awarded a $\mathrm{PhD}$ in Human-Computer Interaction from the University of London.

\section{Introduction}

Tangible interaction is moving from the research lab into real-world spaces (Koleva et al., 2001; Rogers et al., 2004; Zuckerman et al., 2006; Price et al., 2008) such as homes, workplace, learning environments and everyday public places. Indeed, the physicality of tangible and embedded systems makes them ideally suited for use in live performance. For example, tabletop interfaces convert motion on a table surface into music or visuals (e.g. Jam-o-Drum - Blaine and Perkis, 2000; AudioPad - Patten, Recht and Ishii, 2002; reacTable* - Jorda et al., 2005); for live cinema editing in performance cinema (Lew, 2004); and for painterly interfaces (Levin, 2000). While these systems provide interesting toolsets to the performer, few consider the performative aspects of tangible interaction - how the audience and non-performers might understand, respond and interact with a system.

Our position is that the key to designing successful tangible interfaces for the real world is in understanding the practice, methods and theories in the field of Live Art (Sheridan et al., 2004; Sheridan, 2006). These understandings can then be used to inform the design not only of the artefacts themselves, but also the performative context in which they are deployed.

A key domain in which tangible Live Art occurs is Digital Live $\operatorname{Art}^{1}$ (DLA) (Sheridan, 2006) - an emerging field of research that sits at the intersection of computing, Live Art and Human-Computer Interaction (HCI). DLA brings in to question how we design for, and support interaction, which is not conventionally task-based and routine, but experimental, improvisational and fleeting. Such a domain provides a unique environment in which to explore real-world tangible interactions, and yet, we have little understanding of how to design for such situations.

Our particular interest is in the design and application of tangible systems for live performance that are highly mobile and are designed for non-discrete spaces that are temporary and fleeting - much like street theatre and walkabout performance, where passers-by stumble upon the performance by chance. In our research, we seek to promote performative interactions where participants are drawn into, and take part in a performance. This move from the lab to the streets (Benford, 2005; Rogers et al., 2005) raises key research questions about how to design tangible systems. In this paper, we propose and illustrate the key design requirements for performative tangible interactive systems that are as follows.

1 Intuitive - allow people to quickly grasp an understanding of the basic elements of the interaction, rather than being aimed at expert performers.

2 Unobtrusive - allow the public to carry on their normal activities if they choose to.

3 Enticing - encourage spontaneous interaction by passers-by without any, or very little, instruction.

4 Portable - are lightweight and low power, and easily transported, set up and taken down. 
5 Robust - can withstand, and recover from, a range of environmental conditions such as adverse weather and changeable lighting, and different forms of interaction.

6 Flexible - can be dynamically tailored to the environment in which they are deployed.

These requirements cover both the technical and non-technical aspects of tangible design, and clearly there are tensions between these design requirements. For example, there is a tension between designing something that is unobtrusive, yet prominent enough to be enticing. Similarly, there is a tension between designing something that is portable, yet robust enough to withstand rain and harsh physical interaction. To date, these challenging issues are often circumvented by, e.g. developing performances that occur indoors, or in spaces where lighting and other environmental factors can be controlled. In this paper, we outline a set of guidelines for designing performative tangible interaction systems that help resolve these tensions. Our design requirements and guidelines are developed from performative analyses of case studies of DLA in the harsh environment of outdoor music festivals. Our key guidelines focus on: visibility, controllability, robustness and responsiveness.

In the next section, we discuss current research on understanding and designing for performative situations. We then briefly outline our conceptual framework for understanding the performative aspects of tangible interaction, and describe our DLA system. We follow this by demonstrating the use of our framework through four case studies of our system in use at festivals. We conclude by deriving a set of guidelines for DLA design and evaluation.

\section{Background}

Our interest is in how the measures and conceptual frameworks from Live Art can be used to understand and analyse performative interaction (Sheridan et al., 2004; Dix et al., 2005; Benford et al., 2006; Sheridan, 2006) with tangible interfaces, and to tempt spectators into participation and play. Live Art is event-based and often fleeting. It is more anarchic and experimental than a traditional play in that there is not a specific form to follow and it often occurs outside the traditional theatre space (Goldberg, 1998, 2001). An important feature of Live Art is that it is often performed by non-professional performers, which makes it an ideal domain for exploring the issues of designing tangible interaction for public use beyond the traditional Computer Science and HCI repertoire. Previous performance and computing collaborations, particularly in choreography, music and dance (Noll, 1967; Politis, 1990), suggest that drawing on performance knowledge is essential for the creation of new design thinking and practices.

Much of the previous research on HCI and Art focuses on using knowledge from the visual arts to design and develop creative user interfaces (Shneiderman, 2002; Crabtree et al., 2004). Höök, Sengers and Andersson (2003) discuss how interactive artists generally ignore HCI methodologies and how user studies can be suitably adapted for artists. Other researchers present strategies for developing creativity support tools (Candy and Hori, 2003; Jennings and Giaccardi, 2005) and suggest a need for developing comprehensive and appropriate evaluation methodologies that recognise such innovative possibilities (Jennings, 2000). However, these explorations rarely consider performative interaction with tangibles. 
Research on understanding the role of interactive computing in live, public performance has typically maintained a strong distinction between performer and audience and has not explored the nature of transitions from observing to performing. Reeves et al. (2005) present a framework for examining performers' manipulations and their resultant effects yet their framework encompasses all people who interact with a system, regardless of their insight, or virtuosity and cannot be used to capture how spectators become performers (Sheridan, 2006; Sheridan, Bayliss and Bryan-Kinns, 2007a; Sheridan, Bryan-Kinns and Bayliss, 2007b). Moreover, Reeves et al.'s (2005) framework does not account for people who are in the same space as the performance, but not implicated in it.

\subsection{Wittingness and the performance frame}

Benford et al. (2006) distinguish between performers (those who construct the performance) and spectators (those who interpret the performance). Furthermore, they distinguish between 'witting and unwitting' (Sheridan, 2006) spectators respectively, 'audience' members who interpret the performers' actions as a performance and 'bystanders' who may observe performers' actions but do not interpret them as performance. Flintham et al. (2003) illustrates this through a street-based orchestrated performance that mixes digital technology and live performance to explore the boundaries of public game play where members of the general public who are not part of the game may also become involved by implication. However, this framework overlooks a critical third category of behaviour - participating - those who interpret the performance and carry out action within it, but are not experts. Again, this framework does not account for transitions in performative interaction from spectating to participating to performing.

Sheridan (2006) proposes a framework for understanding these transitions, which we draw on later in this paper to reflect on the iterative design of our piece of DLA. The framework takes Bateson's (1955) concept of the 'performance frame' and defines it as the 'cognitive context where the rules of behaviour, symbols and their interpretations are bound within a particular activity within its own structure' (Sheridan, 2006; Benford et al., 2006). For example, when attending a conventional theatre performance we enter into a performance frame that has a particular set of rules of behaviour, which would be quite different to those of attending a football match. We apply this concept to allow us to characterise people's behaviour with respect to the performance frame, and so determine the effect of our tangible technology on their behaviour. Next, we define three categories of behaviour (Sheridan, Bryan-Kinns and Bayliss, 2007b; spectating, participating and performing), which we distinguish in terms of technical ability (whether they have the necessary skills to achieve desired results with the technology), awareness of the performance frame (wittingness; whether they understand and can manipulate the performance frame) and interpretive ability (whether they are able to express meaning and emotion through their interaction).

Spectating can be subdivided into witting audience and unwitting bystanders depending on their awareness of the performance frame; neither audience members nor bystanders engage in performative interaction. They are not interacting with the performance and so they are not exhibiting any technical or interpretive ability. 
Participating in a performance involves developing technical abilities through the acquisition and execution of simple routines - usually through observation and trial and error - while the performance takes place, typically in front of an audience. At this stage their technical abilities are very basic, and so it is difficult for them to express meaning and emotion. They are aware of, and choose to step into the performance frame, but do not possess a deep understanding of it and so cannot change it.

Performing with an interface requires that performers have prior knowledge about the performance frame and the kinds of actions they can undertake. In most cases, they will have practiced their action prior to the performance to increase their technical ability and allow them to express themselves. Moreover, their wittingness and technical abilities allow them to manipulate the performance frame in situ.

We are interested in how to use these distinctions to inform the design and evaluation of tangible devices for spaces that are heavily populated with unwitting bystanders - people who may not be aware of the performance (Benford, 2005; Benford et al., 2006; Sheridan, 2006). However, as Sheridan (2006) and Sheridan, Bryan-Kinns and Bayliss, (2007b) discuss, many people are uncomfortable with participating or performing in public and so there is a need to move beyond techno-centric design to consider strategies for designing for performative interactions that allow the transition of public between various levels of activities.

In order to encourage these transitions, we developed a DLA piece that encourages intense and spontaneous shared performative interaction. We called our system uPoi, which we discuss in the next section.

\section{3 uPoi}

uPoi is a highly portable and wireless, multi-participant, tangible, peer-to-peer DLA aimed at encouraging transitions in witting participation. In contrast to other multiparticipant, performative, public interactions such as discussed in Benford et al. (2006) and Flintham et al. (2003), uPoi focuses on Caillois' concept of Paidia - playing without rules or limits often called 'pure play' rather than Ludus, or pure games which are often rule-bound and introduce the concepts of winning, combat or conflict (Caillois, 2001). Paidia on the other hand, focuses on the often shared, anarchic and spontaneous play found in improvisation. Ludic games often require a large number of skills to be learnt whereas in Paidic play the number of skills required of the performer is kept to a minimum so that play is the central object of activity rather than skill building.

In this paper, we take uPoi into the wild of large outdoor music festivals where we attempt to entice people into unexpected interaction in situations such as walking across a field at $2 \mathrm{am}$. Through the case studies presented later, we illustrate how enticing of people into interaction involves designing both the tangible technology and the performance frame to allow transitions from unwitting bystander to audience, and onto the participant or even the performer.

uPoi is a separate development to iPoi which is explained in detail in Sheridan, Bayliss and Bryan-Kinns (2006a, b, 2007a). It is a tangible version of the traditional Maori art of poi in which balls tied to the ends of string are swung around the body to create patterns as illustrated by the poier performing with poi (Figure 1). uPoi places a greater emphasis on mutual engagement (Bryan-Kinns and Healey, 2007) between people 
than iPoi, like the multi-threaded shared control found in the reacTable* (Jorda et al., 2005). For the sake of clarity, we briefly outline the system here. uPoi consists of three components: sets of uPoi for transmitting data (Figure 2); one computer for receiving acceleration data; and, one computer for producing audio and visuals. Data is sent between computers using a wireless peer-to-peer network. Each uPoi contains one Tmote Sky module (Figure 3), which has wireless transmission capabilities. For our purposes, we utilised the $5 \mathrm{G}$ accelerometer contained in the Tmote Sky module and we developed custom-designed Java code so that we could transmit data from each uPoi ball wirelessly to a computer. A typical set up would involve projecting the visuals onto a screen and through loudspeakers. People interact by spinning the sock with a Tmote Sky in it, or shaking the teddy bear (Figure 3).

Figure 1 A poier performs with poi and creates patterns

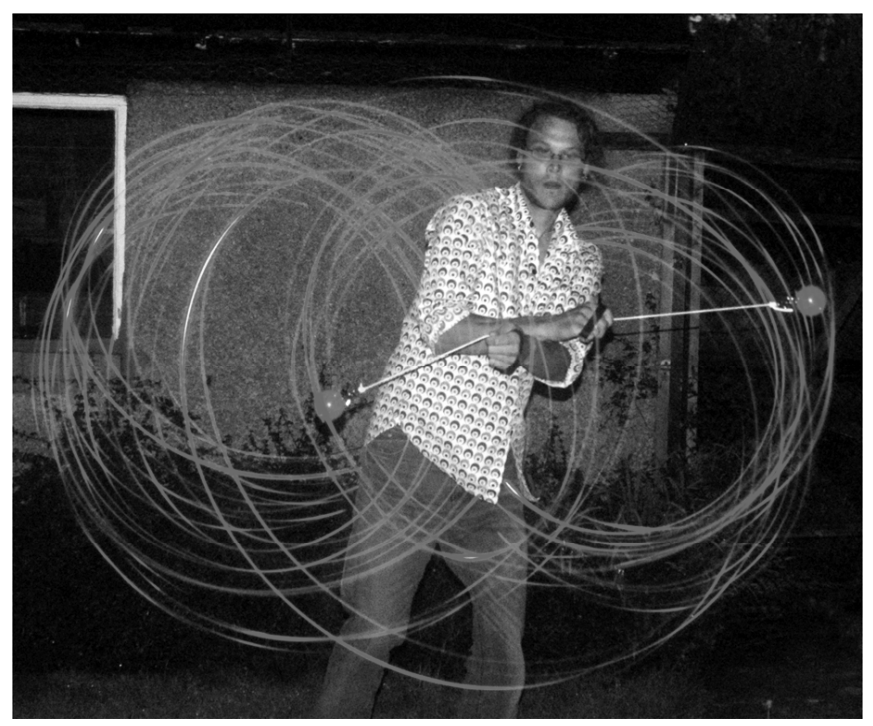

Figure 2 uPoi system configuration

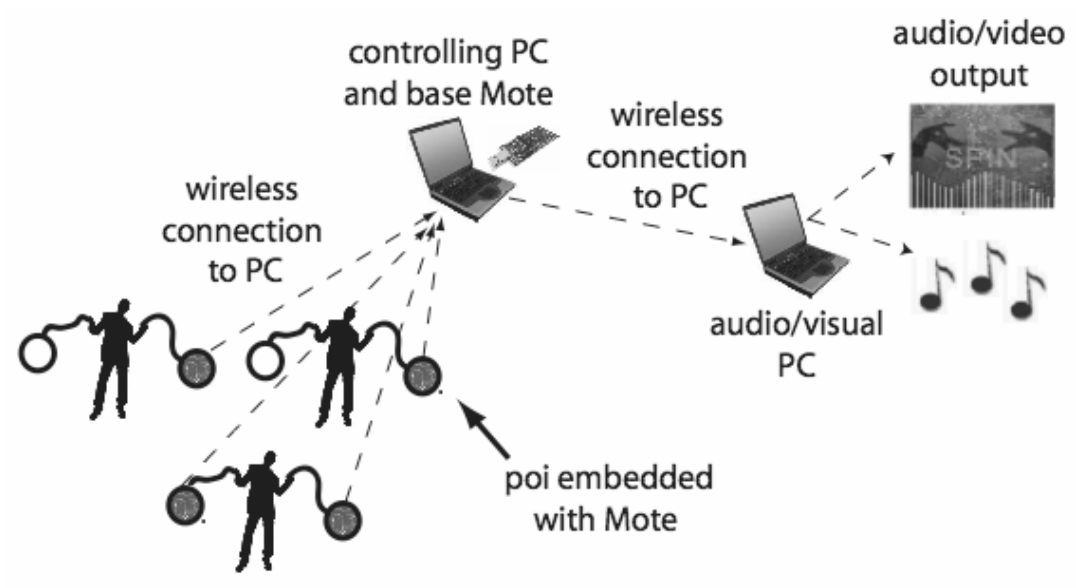


Figure 3 uPoi hardware

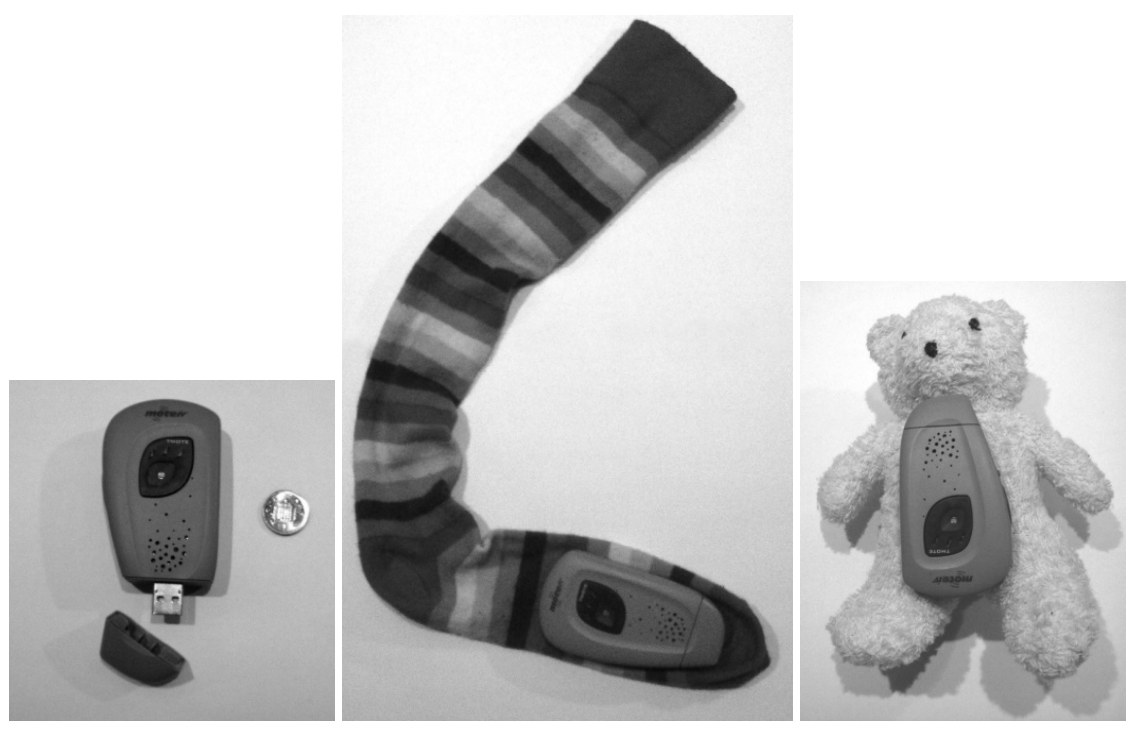

uPoi is an exertion interface (Mueller, Agamanolis and Picard, 2003), which requires the active perception and exploration of objects through intense physical activity. uPoi is different to many tangible systems for live performance that are often impactive controlled through touch (usually by the hand, e.g. Figure 4a) - or gestural - where interaction occurs near a screen (Figure $4 b$ ) - whereas uPoi relies on the physical exertion of swinging an object around the body at a significant distance from (or without) the screen as illustrated in Figure 4c. Moreover, uPoi is unusual in that it relies on continuous interaction - the constant swinging of the uPoi - rather than discrete interaction such as moving an object from one position to another on a tabletop, or pressing a button.

There are a number of advantages of our system for festival performances that we frame in terms of our design requirements.

1 Intuitive - there is a direct link between physical movement of the uPoi and the audiovisual output of the system.

2 Unobtrusive - uPoi is body-centric and moves with the person interacting with it.

3 Enticing - the interaction is visible to passers-by and they can easily enter into the performance frame simply by swinging the uPoi.

4 Portable - our system requires a set of uPoi that can be carried in one hand, one laptop and a projector.

5 Robust - the uPoi are shock-resistant, the software is designed to withstand crashes of subcomponents and does not rely on specialised drivers or hardware.

6 Flexible - as we will discuss in the case studies, flexibility was a critical part of the iterative development of uPoi. 
Figure 4 Three forms of tangible interactions
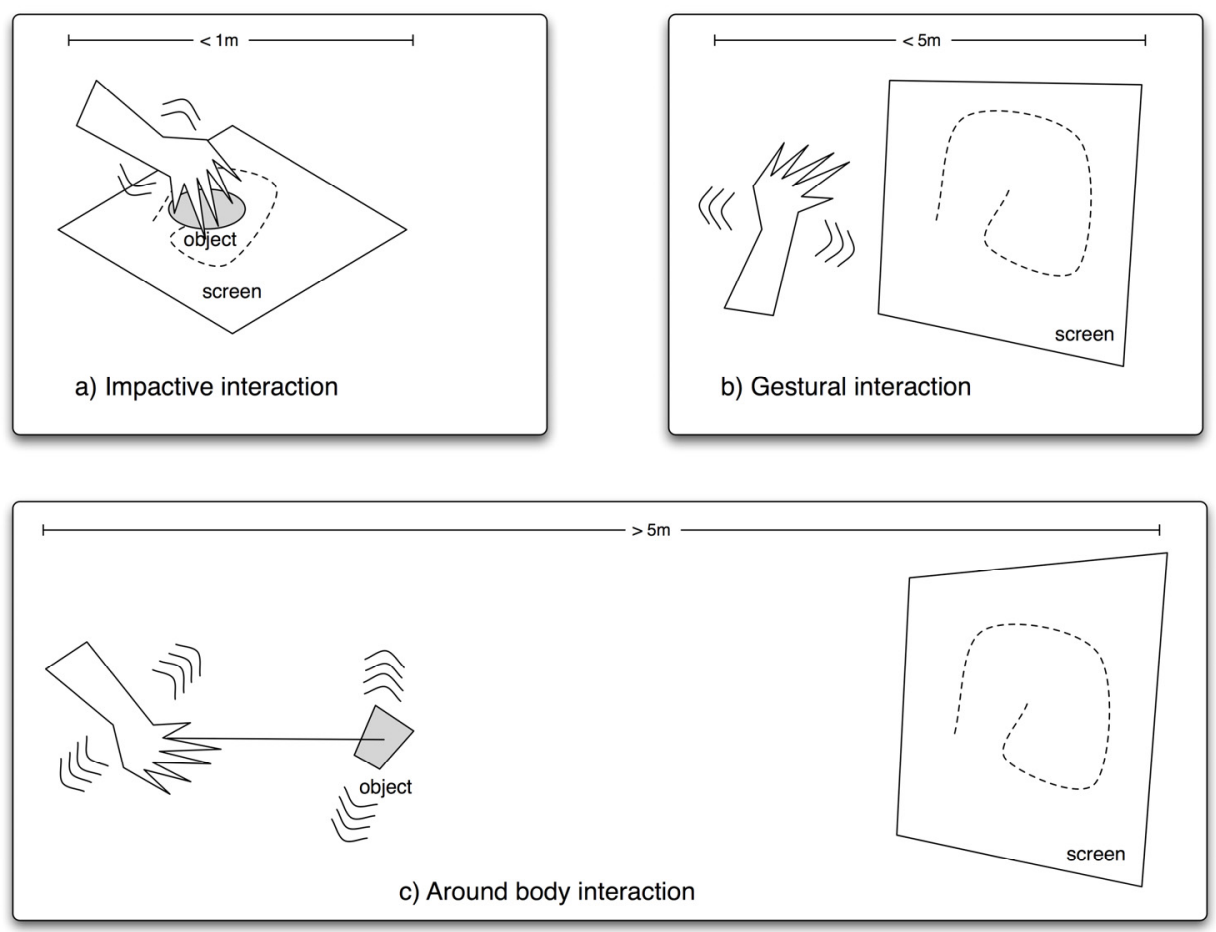

\section{Case studies}

We attended UK music festivals that encouraged uninvited performance and play. This promotes a sense of shared experience like that found in environmental theatre. As Schechner $(1969$, p.177) describes, environmental theatre can be linked to ritual and street life where 'all space is used for performance; all the space is used for audience ... a sense of shared experience can be engendered'. Such festivals provide an ideal environment for exploring the design of tangible interaction as there are a large number of potential participants available (several thousands), and there is the general ethos of participation and exploration.

Figure 5 illustrates part of a typical UK music festival. In this photograph, we see a small food tent - there would be tens of such tents in one festival site - and many festival attendees, some of whom are dressed in costume, and some who have their children with them. In the first two performances described here, we attended as paying members of the public (i.e. without 'artist' passes or VIP access). In the final performances, the festival organisers gave us free entrance. 
Figure 5 Part of a typical UK music festival

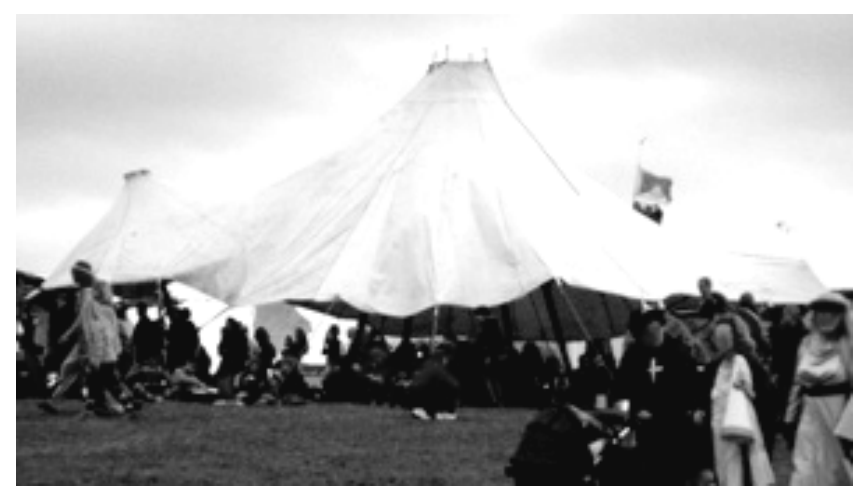

\subsection{General approach to the case studies}

For each case study, one investigator acted as the interactor and was responsible for interacting with the system and any people who wanted to interact. The other investigator was the general observer who took video, interviewed people who watched and used uPoi, and was responsible for writing observations immediately after each performance. After the performances, notes were written on general observations; then, the investigators collaboratively wrote observations and finally reviewed the videos.

During the daytime at each festival we walked around the entire site, looking for tents onto which we could project our visuals. Tents in the arenas varied in size, colour and shape and held anywhere from 10 to $1000+$ people, and usually did not have any visual projections on external surfaces. Almost all tents had some audio playing inside that created a very eclectic sound outside the tents as audio from the various tents blended in with one another. It is important to note that in many cases, the tents were unsuitable for projection because the angle of the roof was too flat, the walls were small, canvas was darkly coloured or there was too much light pollution.

The case studies all reflect on the physical and digital design of the tangible devices, and, importantly, the design of the context in which the devices were used. We use our framework for understanding performative interaction to identify problems and successes with our designs to inform iterative redesign and development of our guidelines and system as illustrated in Figure 6.

\subsection{Case study 1}

Our first festival had over 10 arenas situated in a 20 -acre field. The four-day festival was open to the public of all ages. For this first case study, we took the hardware developed previously (Figures 1 and 2) and, for safety, we wrapped the hard plastic Tmotes in bubble wrap before placing them inside a sock to provide a soft cushion.

We developed three new kinds of interactive visuals for the festival:

1 geometric shapes that moved in response to the uPoi

2 a three-dimensional (3D) landscape in which points of light changed in response to the uPoi

3 a multi-layered forest scene in which celestial lights moved in response to the uPoi. 
Figure 6 Iterative development and refinement of uPoi through case studies

Changes to uPoi between case studies

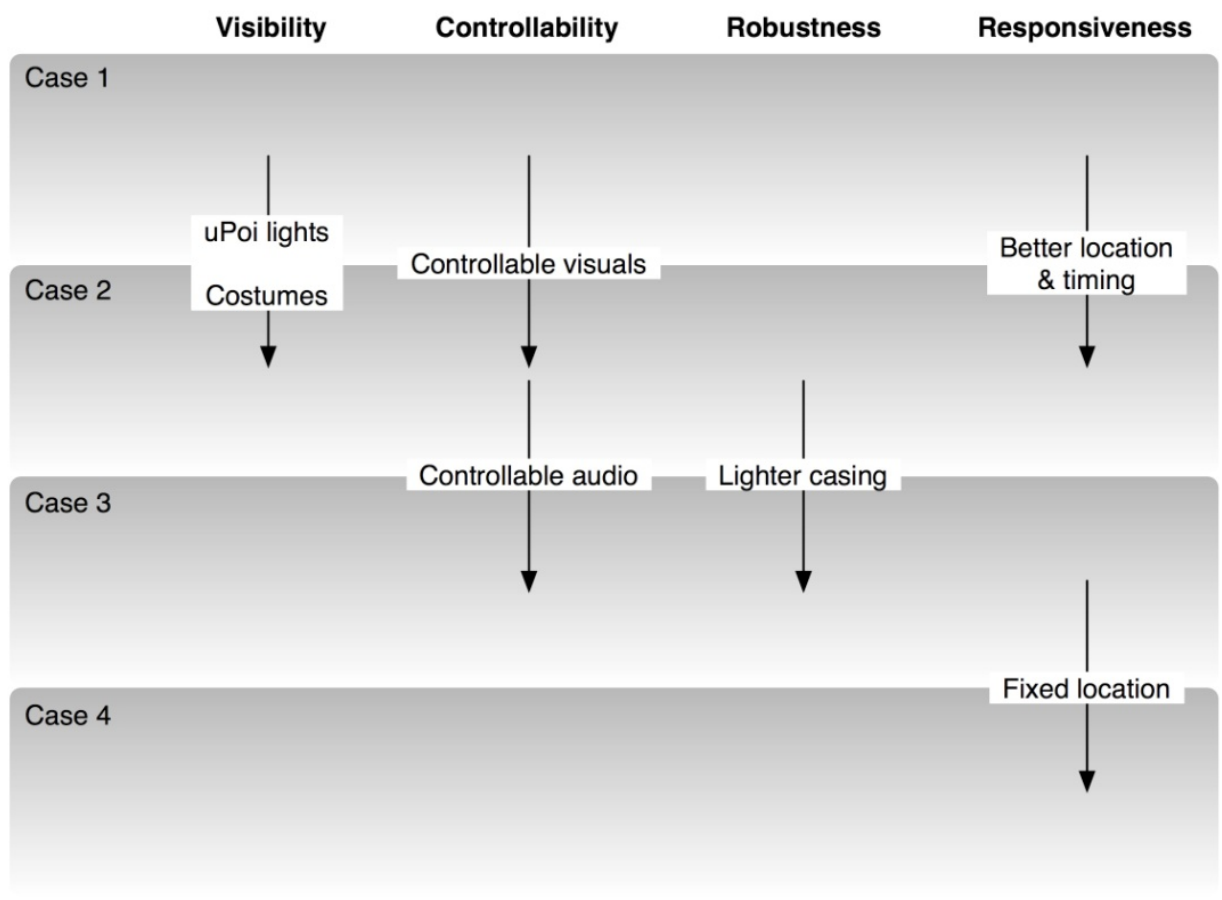

All three visuals had a more direct mapping from uPoi movement to the visuals than in our previous iPoi work in an attempt to make it easier for people to understand how they controlled the visuals - to allow them to develop their technical skills and more easily transition to participant. Moreover, we coordinated the colour of the uPoi socks with the colours of the visuals to give a direct mapping from the sock to the visual layer. Again, this was aimed at enabling the development of technical abilities through clear mapping between tangible device and output.

\subsubsection{Observations}

The session lasted for two hours from about midnight. We located ourselves outside a white 'chill out' tent with ambient sound, and projected onto its roof. Only a few people seemed interested in what we were doing, and we often had to invite people to interact. Essentially our performance frame did not entice people into interaction, people did not realise that there was a performance frame to enter, and if they did, it did not entice them to enter it. This was disappointing! We outline a number of reasons for this, and lessons learnt. 


\subsubsection{Tangible design}

We used red and yellow to distinguish pairs of uPoi that worked fine when tested in the lab, but even though the tent we were projecting on was white, the red colour we used was hardly visible. Our first lesson was that there needed to be real-time control of the colours of the visuals - the performance frame needs to be adaptable to the context. Without strong visuals (or audio), it is not possible for people to develop their technical abilities and transition to participants as they cannot see (or hear) what effect they are having on the DLA. In such a situation, participants cannot develop the skills to perform.

Similarly, the visuals that relied on 3D images looked beautiful in the lab, but were barely visible on the tent. The second lesson learnt was that irregular shape of tent roofs, and the range of ambient lighting (even at $2 \mathrm{am}$ ) meant that simple, strong geometric shapes were the most effective visualisations.

We were using brightly coloured socks for the uPoi, but they were not very visible in the dark. We learnt that really the uPoi needed to emit their own light to be visible at all. Again, this design decision meant that it was not clear to passers-by that a performance was occurring, or could be entered into.

\subsubsection{Context}

During the day, the area was buzzing with people moving in all directions. However, at night, most people headed for the dance tents. We had inadvertently set up in a low traffic area, with very few bystanders. Moreover, we set up at a time when the drink tents were still open and the headline DJs were playing in the massive dance tents. So, our performance frame was located in the wrong space at the wrong time to attract and entice passers-by into entering the performance frame.

We decided to wear waterproof trousers (construction trousers - yellow legs with reflecting silver strips on them) as the ground was wet and it might rain. However, when we were performing people assumed that we were festival workers just taking a break. This meant that our performance frame was not strongly defined and so did not attract people into interaction with the uPoi. We decided that in future performances, we would wear costumes to create a sense of event.

\subsection{Case study 2}

The festival in this case study was similar in size and community ethos to the previous case study and was open to the public of all ages. We developed a user interface in Java so that we could adjust the performance to the physical situation by rapidly choosing between different types (circles, dots, lines) and colours of visual output using dropdown menus and sliders. From our previous performance, we determined that lighting would make the performance frame more obvious, and entice people into it. We wrapped the Tmote (which was already packaged in bubble wrap) with a small string of batterypowered fairy lights. At this festival, the entire site shut down at midnight for a half hour ceremony before starting up again. We decided that the best time to perform was after $2 \mathrm{am}$, when the ceremony finished, most of the alcohol tents were closed and when people were more likely to be wandering between tents looking for different forms of 
interaction - a kind of flux time. We wore costumes that made us somewhat stand out from the crowd in order to identify ourselves as part of a performance and create a sense of event.

\subsubsection{Observations}

We set up outside a large dance tent at 2 am and performed for two to three hours. For about $75 \%$ of the time that we performed with uPoi many people of all ages wittingly participated (up to five at a time). By participating, we mean that people learn and practice simple moves with the uPoi, understand that there is a performance frame, but do not express emotion or meaning through their interaction. Initially, spectators and witting participants did not recognise that uPoi was controlling the visuals that were projected on the tent. Possibly, people thought that these were the normal projections on the tent. Often unwitting bystanders would ask what we were doing, and when we explained that uPoi was creating the visuals they seemed genuinely surprised, excited and interested they exhibited a willingness to participate. Typically people would interact for at least three minutes, learning how to interact and control visuals through trial and error, some playing for up to $30 \mathrm{~min}$. Witting observers and participants said that they noticed the flashing lights on uPoi from a distance. From this, we suggest that a combination of the lights and the activity of uPoi identified a public performance frame and enticed people to performative interaction, which led their curiosity to draw them into participating through simple understanding of the link between the uPoi and the visuals. Unlike case study 1, we did not intervene to get people to interact with uPoi; people exhibited a willingness to interact and were keen to develop their technical abilities in order to participate.

Compared with case study 1, we were much more successful in constructing an enticing performance frame. There are several reasons for this including: locating at a place of high traffic, marking ourselves out as being part of a performance through costume and good visibility of the physical objects and strong relationships between tangible objects and visuals. We will discuss these observations in the rest of this section.

\subsubsection{Tangible design}

The revised visuals with real-time control of colours and shapes worked very effectively. It was possible to change the shapes to keep people's interest in the visuals, and to adjust the colours in response to the changing ambient lighting. However, while adjusting the colour and shapes was enjoyable for the person in control (the interactor), we observed that it was difficult for unwitting bystanders to understand the nature of the performance. In particular, developing the technical ability to control the visuals using the uPoi can be difficult if the connection between the uPoi and the visuals is obscured by the interactor's adjustments to the colours and shapes. Moreover, bystanders get the impression that the interactor is solely controlling the visuals, rather than the uPoi participants directly controlling the visuals. We suggest that there needs to be a careful balance between interactor and participant control.

Adding a set of fairy lights to uPoi definitely drew more attention as unwitting bystanders could see the swinging uPoi from a distance. However, the lights and batteries added a significant amount of weight to each uPoi and so participants' shoulders would 
grow tired quickly. This reduced the amount of time participants could develop their technical abilities, so it would be hard for their transition from participating to performing with uPoi.

\subsubsection{Context}

The space in which we chose to perform was near perfect. We positioned ourselves far enough away from the main entrance so that we were not in the way of people moving in and out or sitting outside of the dance tent. Moreover, the location was in a main route of festival traffic so there were many passing bystanders who had the potential to interact with the system and thus transition to witting spectators or even participants. There was plenty of space for people to swing uPoi and there was a steady stream of people throughout the performance.

Additionally, we chose to perform at a particularly good time of night. The area was very dark - many of the surrounding tents had shut down thus reducing light pollution. There was a lot of activity happening outside the tents - people were wandering the site looking for things to do and for alternatives to dancing. We also found that people wanted to be really physical - the uPoi fit people's mood and desire for physical interaction. So, the physicality of uPoi encouraged people to transition from unwitting bystanders to witting participants.

As predicted, our costumes generated a lot of interest from spectators and enticed interaction. We wore lights inside our costumes, which in turn caused us to interact with spectators in a more performative manner.

\subsection{Case study 3}

Our final two case studies took place at an outdoor festival that restricts its number to 5000 people of all ages. Unlike our first two case studies, we were invited to attend and given free entrance and a map of the site in advance. This time, we intended to set up both visuals and audio. As with the previous case study, we dressed up in costumes to create a sense of performance around the uPoi. We explored a series of physical designs to meet the uPoi requirements of being: small, lightweight, soft and illuminated. Figure 7 illustrates the redesign process: casting moulds for casing from latex rubber (top left) and constructing a latex sheath (top middle). When both these designs proved unusable, we sewed soft pockets - each of which contained a lamb's wool centre (bottom left), a waterproof leatherette holder with attached strings (bottom middle) and a interchangeable exterior pocket with press studs for holding together the materials (bottom right). We punched eyelets into the exterior pocket for coloured ultrabright light emitting diodes and their $3 \mathrm{~V}$ batteries (top right).

In previous studies, our system simply triggered different audio samples that the witting participants and performers used to create collective soundscapes. In order to explore the role of sound in witting transitions with uPoi we recruited a sound engineer who constructed four additional triggered soundscapes, and a generative soundscape, which evolved in response to the movement of the uPoi. Different styles of music were used in the soundscapes from dub reggae to 50 s sci-fi so that the music could be tailored to fit with the environment. We developed real-time controls for the audio so that the volume, balance and tone of each layer could be adjusted in the field. 
Figure 7 Physical redesign of uPoi
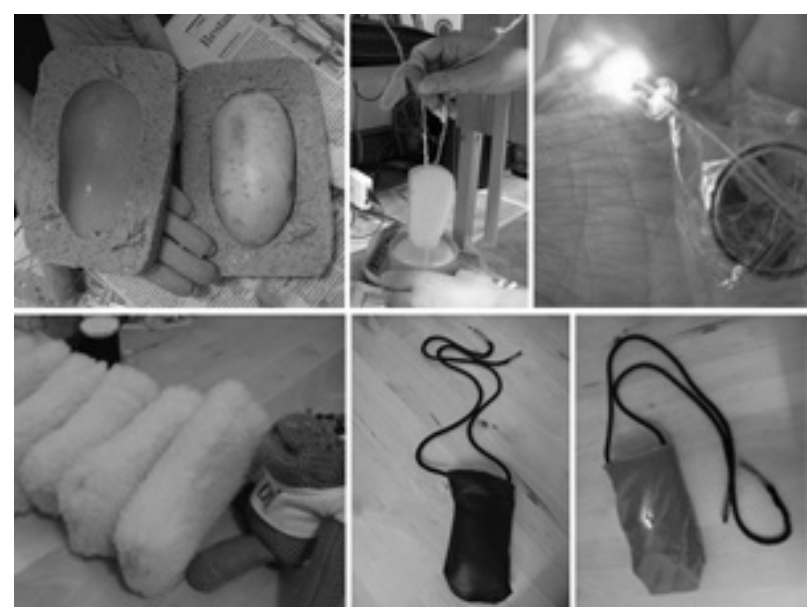

\subsubsection{Observations}

We performed with uPoi for approximately three hours outside a large food tent. Again we had a number of unwitting bystanders approach us as soon as we began to set up our system, and people wittingly interacted together with uPoi for most of the session. In this situation, we had a performance frame that attracted people and enticed them into becoming witting participants in the performance.

We interviewed a number of witting participants who were all very positive about the experience. For example, one man commented, 'The first time you see it [uPoi], you see people spinning these things around, and you just kind of think, that's a load of nonsense, but when you see it connected to the (visuals), the light, and you can see what you're doing with the rhythm ... really good'. The connection witting participants made between their action and the visual projections - a self-learnt understanding of the performance frame we had designed - clearly demonstrated the intuitive nature of the system. Participants' ability to learn how the system worked through trial and error and develop their technical abilities supported their transition from unwitting bystander to witting spectator, and onto witting participant.

Similarly, many experienced poiers' comments indicated that they were able to enter a flow state (Csikszentmihalyi, 1991) with uPoi. For example, an experienced poier who used uPoi for over $30 \mathrm{~min}$ commented, 'You sort of get lost, so you forget what you're actually doing, cos normally when I'm doing poi I'm in my own head, just doing me own thing'. Here, we see a witting performer using her technical and interpretive skills to perform with uPoi to express herself and create visuals in a way she has never done before, without having to concentrate on her interaction with the technology itself.

\subsubsection{Tangible design}

The new uPoi casing worked particularly well. We noted that the reduction in weight allowed witting participants to swing for at least five to ten minutes longer and so develop their abilities more. Although people regularly hit their bodies and their heads 
with the uPoi, in post-interaction interviews, no one suggested that the hit was painful. The lights also proved to entice interaction - they created lighted trails around bodies and made them stand out from other poi in the area, so distinguishing the uPoi performance frame from the traditional poi performance frame.

We found that the bass-based or soft woodwind soundscapes worked most effectively in the outdoor space. As with the visuals, we used the real-time control to adjust the sounds to suit the space or to fit in with the ambient sounds from the surrounding tents. Again, we learnt that when creating this sort of spontaneous performance, it is not possible to know in advance what sort of audio environment will be encountered. However, as with the previous studies of the iPoi system (Sheridan, Bryan-Kinns and Bayliss, 2007b) it was not clear to people what sounds they were controlling, especially when there was a lot of background noise or more than three people interacting with the system. This was especially true of the generative soundscape where participants' movements only had an indirect influence on the sounds produced. The auditory element seemed best considered as influencing an atmosphere with respect to the performance frame, rather than being explicitly controlled.

\subsubsection{Context}

Again, we had set up in a very good area - next to a massive tent with a large number of people outside, and a steady flow of traffic moving in and out. Also, because we were on a slight slope, we were slightly above the crowd passing through to the main stage area, and so were directly in the flow of traffic leaving there.

Having an additional investigator on hand to interact with uPoi was excellent - again, this gave the investigators more time to observe transitions in performative interaction and to take video. The witting performer acted as an enticement to interact - spectators could sit back and watch (transitioning from unwitting bystander to witting spectator), and could easily pick up the uPoi to transition to participant.

\subsection{Case study 4}

\subsubsection{Observations}

We performed for four hours in a tent that a festival merchant loaned to us (Figure 8). Transitions in witting participation and performance were exceptional. A large group of expert poiers unexpectedly arrived and spent a lot of time performing as a group with uPoi, asking technical questions and trying to outperform each other. Typically they would spend half their time watching the visuals, and half the time with their back to the visuals demonstrating their technical and interpretive abilities. The presence of a number of expert poiers caused non-experts to interact with uPoi away from the tent, or to the side of the tent. Additionally, some people preferred to interact with the augmented teddy bear as it provided 'inconspicuous interaction' (Sheridan, Bryan-Kinns and Bayliss, 2007b). 
Figure 8 Enclosed tent used in case study 4

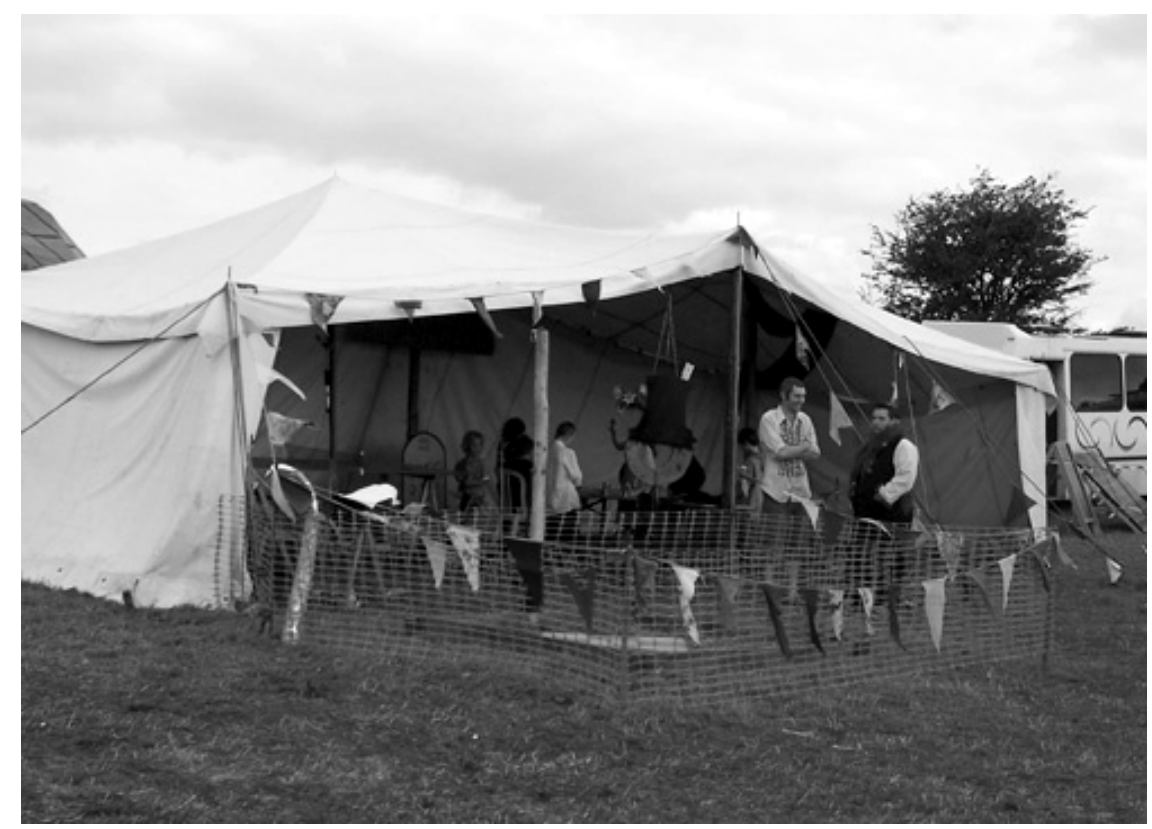

In some respects, this case study was the most conventional setup - we had a particular space in which people could interact (though, of course, they could play with uPoi anywhere) - and there was a group of expert poiers. To this extent, this case study illustrates uPoi's support for transitioning from unwitting bystander to performer without any explicit instruction as discussed in the rest of this section.

\subsubsection{Tangible design}

In all of the case studies, the sound was at its best in this one as it occurred in a confined space and so we were able to control it in real time. However, the proximity to an adjacent dance tent meant that our sound could not be heard outside our tent and so did not act to entice people into the space. Again, the soundscapes helped to define the extent of the performance frame rather than being something participants wittingly controlled, as was our original intention.

\subsubsection{Context}

The flow of traffic was much different to our previous cases - our close proximity to a disco tent meant that many bystanders came into the space to dance and then happened upon us. Moreover, as we were located inside a tent, it was less likely that bystanders could see the visuals unless they came towards the tent (or the disco tent). However, performing inside the tent also gave uPoi less of a guerrilla feel, and more of a feeling of being part of the festival itself.

The space was exceptionally good for witting participation in that there was a lot of space for people to interact and develop their technical skills and, as they were right beside the visuals that they were creating, there was a direct link between their 
movements and the visual and audio outputs, so they could learn through trial and error. Unlike our other cases, setting up our equipment away from the performance area allowed us more freedom to speak with and observe witting participants as well as perform ourselves. This also allowed us to invite curious participants into the technical area so that they could manipulate the graphical user interface (GUI) if they wished to do so.

\section{Guidelines}

In the case studies just outlined, we reported our experiences of iteratively designing a tangible system using the concept of performance framing to inform redesign. We used our concept of wittingness to focus our design and evaluation questions. Asking ourselves about people's wittingness (e.g. whether people were aware of the performance frame, whether they were participating or spectating and why), their technical abilities (how they developed them, and what hindered learning) and interpretive abilities (what range of technical skills did they need to express themselves) helped us to design a more enticing DLA piece in terms of technology (e.g. the physical casings and the visualisations) and context (e.g. the use of costumes to establish a performance frame).

From our experience, we believe that posing design questions in terms of the performance frame (technical skills, wittingness, interpretive abilities) and witting transitions can drive design decisions and maintain a balance between the technology and performance. We believe that this approach is applicable to tangible design in other realworld domains such as public displays, home gaming, collaborative brainstorming and so on. Based on our observations and experience, we use the rest of this section to suggest a number of practical guidelines for creating wireless mobile tangible DLA. The intention of these guidelines is to move beyond a focus on the technology and interaction, to explore wider design issues pertaining to the performance frame.

\subsection{Tangible design}

The key to tangible design is that the elements have to be visible. This helps to make the performance frame visible, and so allows people to quickly learn simple routines that had an effect in the performance frame. For us this meant:

- Increasing the visibility of the central tangible interaction object by matching the colour of the visuals with the colour of each uPoi (first with socks and later with lights).

- Ensuring that there was as clear and responsive a link as possible between the movement of the uPoi and the audio and visuals produced. The iteratively developed visuals became simpler, higher in contrast and bolder in colour as the case studies progressed. We believe that this visible link directly contributed to the ease of witting transitions. In contrast, the audio soundscapes (especially the algorithmic soundscape) did not exhibit such a clear link, which reduced their contribution to transitions in wittingness. 
It is this dual visibility that allows people to learn simple interaction routines with no instruction and so intuitively transition from bystander to participant, and performer. While we focussed on the visuals in this paper, it is important to note that in some cases audio can provide a more direct link between physical activity and digital output (Sheridan, Bryan-Kinns and Bayliss, 2007b).

Working outside and in the dark produces many unexpected obstacles that need to be overcome. Therefore, the tangible system should be as controllable as possible, for instance, being able to change shapes and colours of visuals in real time so that high-contrast, clear visuals can be produced in a variable environment. Again, being able to produce high-contrast visuals is key to keeping the interaction visible, and contributes to people's abilities to transition between levels of wittingness. Working outside also means having a robust set up, e.g. taking two kinds of networking technologies in case one technology does not work owing to environmental factors. It also means ensuring that all objects are robust enough to withstand rain, accidental damage, dynamic reconfiguration and so on. A performance that requires frequent technical maintenance will not entice people, especially in an environment with many competing sources of entertainment.

Tangible systems for performative interaction work well when they are body-centric and unobtrusive. For example, with our system, participants never separate their body from the system or step away from the system - it continuously moves with and around participants, yet they can disengage with minimal effort. However, one must consider that not all participants want to be the focus of attention and provide alternative forms of tangible participation (such as with inconspicuous interfacing).

\subsection{Context}

Costumes and experts help identify people involved in the performance, make the performance frame visible and provide an illustration of the potential technical and expressive abilities that could be learnt. Moreover, in the festival situation, costumes and experts can entice bystanders into the performance frame.

The flow of traffic changes significantly from hour to hour and from day and night. What appears to be a busy thoroughfare by day becomes a cul-de-sac at night. Also, at festivals, people's state of mind changes quite radically from one hour to another, so timing is crucial. For an exertion interface, it seemed that people were most receptive after the main acts had finished, and setting up at 'pinch points' between venues gave the greatest possibility to passers-by being enticed into the interaction. Identifying appropriate times and spaces for your performance frame can only be done in situ, and relies on good judgement and experience to be responsive to the changing environment.

\subsection{Paidia}

Reducing the number of skills needed to interact with tangible systems encourages witting participation and play. Festivals are extremely good spaces for enticing pure play. For example, with uPoi the simple act of swinging allowed participants to join in the performance and become part of a collective and playful experience. From our perspective, we lifted the burden of instructing participants on the rules of interaction and simply let them play. From the participants' perspectives, this provided a source of entertainment that suited their need for playful encounters in this environment. 


\section{Summary}

In this paper, we described the design and iterative development of a DLA piece - uPoi which aimed to entice witting transitions in multi-participant tangible performative interaction. We showed how the concept of wittingness could be used to drive evaluation and design, and presented some initial guidelines for designing enticing DLA for highly mobile tangible outdoor performances. We propose that these guidelines are applicable in other tangible interaction domains that involve groups of people in real-world interaction. In particular, we suggest that real-world tangible interfaces should be: robust, intuitive, unobtrusive yet enticing, portable and flexible. Our future work looks to improve the enticing qualities of the DLA and develop richer data-gathering techniques for harsh environments such as the use of mobile phones and text messaging.

\section{Acknowledgements}

The authors thank Matt Cooper, Robin Fencott, Sarah Atkinson and the festival participants and organisers.

\section{References}

Bateson, G. (1955) ‘A theory of play and fantasy', Psychiatric Research Reports, Vol. 2, pp.39-51.

Benford, S. (2005) 'Pushing the boundaries of interaction in public', Interactions, Vol. 12, pp.57-58.

Benford, S., Crabtree, A., Reeves, S., Flintham, M., Drozd, A., Sheridan, J.G. and Dix, A. (2006) 'The frame of the game: blurring the boundary between fiction and reality in mobile experiences', Paper presented in the Proceedings of the CHI2006. Montreal, Canada: ACM Press, pp.427-436.

Blaine, T. and Perkis, T. (2000) 'The Jam-O-Drum interactive music system: a study in interaction design', Paper presented in the Proceedings of the DIS 2000. New York, NY: ACM Press, pp.165-173.

Bryan-Kinns, N. and Healey, P.G.T. (2007) 'Exploring mutual engagement in creative collaborations', Paper presented in the Proceedings of the Creativity and Cognition 2007. Washington, DC: ACM Press, pp.223-232.

Caillois, R. (2001) Man, play and games (Les jeux et les homes) (M. Barash, Trans.). Chicago, IL: University of Illinois Press (original work published in 1958).

Candy, L. and Hori, K. (2003) 'The digital muse: HCI in support of creativity: 'creativity and cognition' comes of age: towards a new discipline', Interactions, Vol. 10, pp.44-54.

Crabtree, A., Benford, S., Rodden, T., Greenhalgh, C., Flintham, M., Anastasi, R., Drozd, A., Adams, M., Ju Row-Farr, J., Tandavanitj, N. and Steed, A. (2004) 'Orchestrating a mixed reality game 'on the ground", Paper presented in the Proceedings of the CHI 2004. Vienna, Austria: ACM Press, pp.391-398.

Csikszentmihalyi, M. (1991) Flow: The Psychology of Optimal Experience. New York, NY: Harper Collins.

Dix, A., Sheridan, J.G., Reeves, S. and Benford, S. (2005) 'Formalising performative interaction', Proceedings of the DSV-IS 05, Springer Lecture Notes in Computer Science. Berlin, Germany: Heidelberg, pp.15-25.

Flintham, M., Benford, S., Anastasi, R., Hemmings, T., Crabtree, A., Greenhalgh, C., Tandavanitj, N., Adams, M. and Row-Farr, J. (2003) 'Where on-line meets on the streets: experiences with mobile mixed reality games', Paper presented in the Proceedings of the CHI 2003. Ft. Lauderdale, FL: ACM Press, pp.569-576. 
Goldberg, R. (1998) Performance: Live Art since the 60s. London, UK: Thames and Hudson.

Goldberg, R. (2001) Performance Art: From Futurism to Present. London, UK: Thames and Hudson.

Harris, E., Fitzpatrick, G., Rogers, Y., Phelps, T. and Price, S. (2004) 'From Snark to Park: lessons learnt moving pervasive experiences from indoors to outdoors', Paper presented in the Proceedings of the 5th Australasian User Interface Conference, Australian Computer Society, Inc., Vol. 28, pp.39-48.

Höök, K., Sengers, P. and Andersson, G. (2003) 'Sense and sensibility: evaluation and interactive art', Paper presented in the Proceedings of the CHI 2003. Fort Lauderdale, FL: ACM Press, pp.241-248.

Jennings, P. (2000) 'New media arts|new funding models', Report for Creativity and Culture. New York, NY: The Rockefeller Foundation.

Jennings, P. and Giaccardi, E. (2005) Creativity Support Tools for and by the New Media Arts Community. NSF Creativity Support Tools Workshop, US National Science Foundation, Washington, DC.

Jorda, S., Kaltenbrunner, M., Geiger, G. and Bencina, R. (2005) 'The reacTable*', Paper presented in the Proceedings of the International Computer Music Conference (ICMC 2005), Barcelona, Spain, pp.579-582.

Koleva, B., Taylor, I., Benford, S., Fraser, M., Greenhalgh, C., Schnädelbach, H., vom Lehn, D., Heath, C., Row-Farr, J. and Adams, M. (2001) 'Orchestrating a mixed reality performance', Paper presented in the Proceedings of the CHI 2001. Portland, OR: ACM Press, pp.38-45.

Levin, G. (2000) 'Painterly interfaces for audiovisual performance', MS thesis, MIT, USA.

Lew, M. (2004) 'Live cinema: designing an instrument for cinema editing as a live performance', Paper presented in the Proceedings of the NIME 2004. Hamamatsu, Japan, pp.144-149.

Mueller, F., Agamanolis, S. and Picard, R. (2003) 'Exertion interfaces: sports over a distance for social bonding and fun', Paper presented in the Proceedings of the CHI 2003. Fort Lauderdale, FL: ACM Press, pp.561-568.

Noll, A.M. (1967) 'Choregraphy and computers', Dance Magazine, January, pp.43-45.

Patten, J., Recht, B. and Ishii, H. (2002) 'Audiopad: a tag-based interface for musical performance', Paper presented in the Proceedings of the NIME-02, Dublin, Ireland.

Politis, G. (1990) 'Computers and dance: a bibliography', Leonardo, Vol. 23, MIT Press, pp.87-90.

Price, S., Sheridan, J.G., Falcāo, T.P. and Roussos, G. (2008) 'Towards a framework for investigating tangible environments for learning', Int. J. Arts and Technology, this issue.

Reeves, S., Benford, S., O’Malley, C. and Fraser, M. (2005) 'Designing the spectator experience', Paper presented in the Proceedings of the CHI 2005. Portland, OR: ACM Press, pp.741-750.

Rogers, Y., Price, S., Randell, C., Stanton-Fraser, D., Weal, M. and Fitzpatrick, G. (2005) 'Ubi-learning: integrating outdoor and indoor learning experiences', Communications of ACM, Vol. 48, pp.55-59.

Rogers, Y., Price, S., Fitzpatrick, G., Fleck, R., Harris, E., Smith, H., Randell, C., Muller, H., O'Malley, C., Stanton, D., Thompson, M. and Weal, M.J. (2004) 'Ambient wood: designing new forms of digital augmentation for learning outdoors', Paper presented in the Proceedings of the Interaction Design and Children, Columbia, MD: ACM Press, pp.3-10.

Schechner, R. (1969) Public Domain: Essays on the Theater. Indianapolis, IN, USA: BobbsMerrill.

Sheridan, J.G. (2006) 'Digital Live Art: mediating wittingness in playful arenas,' PhD thesis, Lancaster University, UK.

Sheridan, J.G., Bayliss, A. and Bryan-Kinns, N. (2006a) 'iPOI', Paper presented in the Proceedings of the First International Symposium on Culture, Creativity and Interaction Design, Queen Mary, University of London, UK, September 12, 2006.

Sheridan, J.G., Bayliss, A. and Bryan-Kinns, N. (2006b) 'iPoi: acceleration as a medium for Digital Live Art', Demonstration in Proceedings of Ubicomp2006, Orange County, CA, USA. 
Sheridan, J.G., Bayliss, A. and Bryan-Kinns, N. (2007a) 'The interior life of iPoi: objects that entice witting transitions in performative behaviour', Int. J. Performance Arts and Digital Media, Vol. 3, UK, pp.17-36, Intellect, Bristol.

Sheridan, J.G., Bryan-Kinns, N. and Bayliss, A. (2007b) 'Encouraging witting participation and performance in Digital Live Art', People and Computers XXI-Design for Life: 21st British HCI Group Annual Conference, Lancaster, UK; Berlin, Germany: Springer, pp.13-23.

Sheridan, J.G., Dix, A., Lock, S. and Bayliss, A. (2004) 'Understanding interaction in ubiquitous guerrilla performances in playful arenas', in Fincher, P. Markopolous, D. Moore and R. Ruddle (Eds), People and Computers XVIII - Design for Life: 18th British HCI Group Annual Conference. London, UK: Springer-Verlag, pp.3-17.

Shneiderman, B. (2002) Leonardo's Laptop: Human Needs and New Computing Technologies. Cambridge, MA: The MIT Press.

Zuckerman, O., Pares, N., Benford, S. and Lund, H.H. (2006) 'Designing interactive environments for outdoors gaming and play', Paper presented in the Proceedings of the CHI 2006. SIGs, 2, Montreal, Canada, pp.419-422.

\section{Note}

${ }^{1}$ http://www.digitalliveart.com 